\title{
Serum TSH level stability after 5 years in euthyroid adults at low risk for thyroid dysfunction
}

Pedro Weslley Rosario', Maria Regina Calsolari

${ }^{1}$ Programa de Pós-Graduação e Serviço de Endocrinologia, Santa Casa de Belo Horizonte, Belo Horizonte, MG, Brasil

\section{Correspondence to:} Pedro Weslley Rosario Instituto de Ensino e Pesquisa Santa Casa de Belo Horizonte. Rua Domingos Vieira, 590 30150-240 - Belo Horizonte, MG Brasil

pedrowsrosario@gmail.com

Received on Set/09/2016 Accepted on Apr/25/2017

DOI: 10.20945/2359-3997000000037

\begin{abstract}
Objective: To evaluate changes in thyroid function after 5 years, the interval proposed for new assessment, in initially euthyroid adults. Subjects and methods: Initially, 1,426 apparently healthy adults considered low risk for thyroid dysfunction, were evaluated by measurement of TSH. After 5 years, 1,215 (85.2\%) subjects were reevaluated. Results: After 5 years, four subjects were receiving levothyroxine (L-T4) replacement therapy and 25 others hadTSH $>4 \mathrm{mIU} / \mathrm{L}$, only two of them with TSH $>10 \mathrm{mlU} / \mathrm{L}$. All of these subjects hadTSH $>3 \mathrm{mlU} / \mathrm{L}$ in the initial evaluation. During reassessment, none of the subjects had been or was treated for hyperthyroidism and 22 hadTSH $<0.4 \mathrm{mIU} / \mathrm{L}$ (none of them $<0.1 \mathrm{mlU} / \mathrm{L}$ ). Nineteen of these subjects hadTSH $\leq 0.6 \mathrm{mlU} / \mathrm{L}$ in the initial evaluation. Among the 1,098 subjects with TSH between 0.6 and $3 \mathrm{mIU} / \mathrm{L}$ in the initial evaluation, reassessment showed that none of the subjects was using L-T4; only three hadTSH $>4 \mathrm{mlU} / \mathrm{L}$ (none of them $>10 \mathrm{mlU} / \mathrm{L}$ ); none had been or was treated for hyperthyroidism, and only three hadTSH $<0.4 \mathrm{mIU} / \mathrm{L}$ (none of them $<0.1 \mathrm{mIU} / \mathrm{L}$ ). These results did not differ between men and women or between subjects $\leq 60$ and $>60$ years. Conclusion: RepeatTSH measurement within an interval of only 5 years would not be cost-effective in adults without known thyroid disease or risk factors for dysfunction who exhibit TSH between 0.6 and $3 \mathrm{mIU} / \mathrm{L}$. Arch Endocrinol Metab. 2018;62(3):362-5
\end{abstract}

Keywords

Serum TSH; adults; screening; repetition; 5 years

\section{INTRODUCTION}

A lthough no consensus exists regarding age, some societies including the American Thyroid Association (1) and Brazilian Society of Endocrinology and Metabolism [SBEM in the Portuguese acronym] (2) recommend screening for thyroid dysfunction by serum TSH measurement in asymptomatic adults $(1,2)$. In the case of individuals that exhibit normal TSH concentrations in the initial evaluation, a new measurement is recommended after 5 years (1-3). This interval was defined more because it is the recommended interval for periodic assessments of general health rather than resulting from a specific analysis of changes in thyroid function (1).

We previously evaluated thyroid function in healthy adults considered low risk for thyroid dysfunction $(4,5)$. These adults were reevaluated after 5 years, the interval proposed for repetition in initially euthyroid adults (13 ), in order to verify changes in thyroid function in these subjects.

\section{SUBJECTS AND METHODS}

This study was a reevaluation of two previous studies that evaluated the TSH reference values for Brazilian population. The initial results of those studies were published previously $(4,5)$. Initially, 2,532 apparently healthy adults (age $>18$ years), not including pregnant women, were interviewed $(4,5)$. Of these, 2,327 subjects agreed to participate in the study. Nine hundred and one subjects were excluded because of high-risk factors for thyroid disease or conditions potentially interfering with thyroid function detected upon clinical evaluation (Table 1) (4,5). The final sample consisted of 1,426 apparently healthy adults considered low risk for

Table 1. Inclusion criteria

Absence of thyroid disease, no current or previous treatment with antithyroid drugs or L-T4, no history of ${ }^{131}$ I therapy or thyroidectomy

No use of potentially interfering medications such as dopaminergic agonists or antagonists, neuroleptics, corticosteroids, estrogen, amiodarone, interferon, lithium, anticonvulsants, metformin, octreotide; or recent (in the past 8 weeks) exposure to iodinated contrast agents

No history of head and neck external radiotherapy

Absence of type 1 diabetes or other autoimmune diseases

No family history of thyroid disease

Absence of goiter or any palpable thyroid anomaly

Absence of ophthalmopathy

Normal free T4 
thyroid dysfunction without known interfering factors $(4,5)$. TSH was obtained in the initial evaluation.

After 5 years, these subjects were invited for a new clinical evaluation and TSH measurement. Of the 1,426 subjects included, 1,215 (85.2\%) were reevaluated (605 men and 610 women, 915 with age $\leq 60$ years and 300 with age $>60$ years). Reassessment was not possible in the remaining subjects because of failure to contact them, change of city, and refusal to participate.

The study was prospective and was approved by the local Research Ethics Committee.

Serum samples were obtained from the subjects in the morning (at about 8 a.m.) after an 8 - to 10 -h fast. TSH was measured with a chemiluminescent assay (Immulite 2000, Diagnostic Products Corporation, Los Angeles, $\mathrm{CA}$ ), with functional sensitivity of $0.02 \mathrm{mIU} / \mathrm{L}$, and intra- and interassay coefficients of variation $<7 \%$ for values ranging from 0.1 to $40 \mathrm{mIU} / \mathrm{L}$.

The Fisher's exact test was used for statistical analysis (comparison between the two groups). A P-value less than 0.05 was considered significant.

\section{RESULTS}

After 5 years, four subjects were receiving levothyroxine (L-T4) replacement therapy initiated because of confirmed subclinical hypothyroidism and 25 others had TSH $>4 \mathrm{mIU} / \mathrm{L}$, only two of them with TSH $>10$ $\mathrm{mIU} / \mathrm{L}$. It is worth noting that all subjects receiving L-T4 therapy and 22 subjects with $\mathrm{TSH}>4 \mathrm{mIU} / \mathrm{L}$ (including the two with TSH $>10 \mathrm{mIU} / \mathrm{L}$ ) had TSH $>3 \mathrm{mIU} / \mathrm{L}$ in the initial evaluation.

During reassessment, none of the subjects had been or was treated for hyperthyroidism and 22 had TSH <
$0.4 \mathrm{IUI} / \mathrm{L}$ (none of them with TSH $<0.1 \mathrm{mIU} / \mathrm{L}$ ). It is worth noting that 19 subjects with $\mathrm{TSH}<0.4 \mathrm{mIU} / \mathrm{L}$ had levels $\leq 0.6 \mathrm{mIU} / \mathrm{L}$ in the initial evaluation.

Among the 1,098 subjects with TSH between 0.6 and $3 \mathrm{mIU} / \mathrm{L}$ in the initial evaluation, reassessment revealed that none of them was receiving L-T4; only three had TSH $>4 \mathrm{mIU} / \mathrm{L}$ (none of them with TSH $>10 \mathrm{mIU} / \mathrm{L}$ ); none of the subjects had been or was treated for hyperthyroidism, and only three had TSH < $0.4 \mathrm{mIU} / \mathrm{L}$ (none of them with $\mathrm{TSH}<0.1 \mathrm{mIU} / \mathrm{L}$ ). Among the subjects with initial TSH between 0.6 and 3 $\mathrm{mIU} / \mathrm{L}$, the proportions of subjects with TSH of $0.4-4$ $\mathrm{mIU} / \mathrm{L},<0.4 \mathrm{mIU} / \mathrm{L}$ or $>4 \mathrm{mIU} / \mathrm{L}$ after 5 years were the same in men $(\mathrm{n}=546: 0.18 \%, 99.45 \%$, and $0.37 \%$, respectively) and women ( $\mathrm{n}=552: 0.36 \%, 99.46 \%$, and $0.18 \%$, respectively) and in subjects $£ 60$ years ( $\mathrm{n}=822$ : $0.24 \%, 99.51 \%$, and $0.24 \%$, respectively) and $>60$ years $(\mathrm{n}=276: 0.36 \%, 99.28 \%$, and $0.36 \%$, respectively).

The results of reassessment after 5 years according to initial TSH are shown in Table 2.

\section{DISCUSSION}

The results of the present study confirm that in subjects without known thyroid disease, but with a slightly reduced TSH measurement (0.2-0.4 mIU/L), spontaneous TSH normalization in the subsequent measurement is common (6). Even if normalization does not occur, persistence of the initial finding is more common than progression to TSH $<0.1 \mathrm{mIU} / \mathrm{L}$ or clinical hyperthyroidism $(6,7)$. The same applies to adults with slightly elevated TSH $(4-6 \mathrm{mIU} / \mathrm{L})$ $(6,8,9)$, with the observation of TSH normalization in approximately $40 \%$ and persistence of slightly elevated

Table 2. Results of reassessment after 5 years according to initial serum TSH

\begin{tabular}{|c|c|c|c|c|c|c|c|}
\hline \multirow{2}{*}{$\begin{array}{l}\text { Initial TSH } \\
\text { (mIU/L) }\end{array}$} & \multicolumn{7}{|c|}{ Reassessment after 5 years } \\
\hline & $\begin{array}{c}\text { Treatment for } \\
\text { hyperthyroidism }\end{array}$ & TSH $<0.1 \mathrm{mIU} / \mathrm{L}$ & TSH 0.1-0.4 mIU/L & TSH 0.4-4 mIU/L & TSH 4-10 mlU/L & $\mathrm{TSH}>10 \mathrm{mlU} / \mathrm{L}$ & $\begin{array}{c}\text { Under L-T4 } \\
\text { therapy }\end{array}$ \\
\hline $\begin{array}{l}<0.4(0.2-0.38) \\
(n=25)\end{array}$ & 0 & 0 & $13(52 \%)$ & $12(48 \%)$ & 0 & 0 & 0 \\
\hline $0.4-0.6(n=25)$ & 0 & 0 & $6(24 \%)$ & $19(76 \%)$ & 0 & 0 & 0 \\
\hline $\begin{array}{l}0.6-3 \\
(n=1,098)\end{array}$ & 0 & 0 & $3(0.27 \%)$ & $1092(99.45 \%)$ & $3(0.27 \%)$ & 0 & 0 \\
\hline $3-4(n=38)$ & 0 & 0 & 0 & $30(79 \%)$ & $5(13 \%)$ & $1(2.6 \%)$ & $2(5.2 \%)$ \\
\hline $\begin{array}{l}>4^{*} \text { (up to 5.84) } \\
\text { (n }=29)\end{array}$ & 0 & 0 & 0 & $11(37.9 \%)$ & $15(51.7 \%)$ & $1(3.4 \%)$ & $2(6.9 \%)$ \\
\hline
\end{tabular}

* None of the 24 patients without TPOAb in the initial assessment was treated with L-T4, 11 had normal TSH, and 13 continued to have elevated TSH but $<10$ mlU/L. Among the 5 patients with $\mathrm{TSH}>4 \mathrm{mlU} / \mathrm{L}$ and positive TPOAb in the initial assessment, 2 had elevated TSH $<10 \mathrm{mlU} / \mathrm{L}$, one had TSH $>10 \mathrm{mlU} / \mathrm{L}$, and 2 were taking L-T4. 
TSH in $50 \%$, while progression to TSH $>10 \mathrm{mIU} / \mathrm{L}$ or need for L-T4 after 5 years is observed in only $10 \%$. The consensual recommendation is to repeat the test in these individuals with slightly altered TSH before any treatment decision (10-12). Another implication of this observation is that in population studies evaluating the association between thyroid function and certain outcome(s), but obtaining only a single TSH measurement, a large proportion of the subjects with slightly altered TSH may, in fact, not have true thyroid dysfunction.

The most relevant finding of the study was that, among subjects without known thyroid disease or risk factors for thyroid dysfunction and with initially normal TSH $(0.4-4 \mathrm{mIU} / \mathrm{L})$, none had TSH $<0.1$ $\mathrm{mIU} / \mathrm{L}$ and only $0.25 \%$ had TSH $>10 \mathrm{mIU} / \mathrm{L}$ after 5 years. Most subjects who progressed to reduced (but $>0.1 \mathrm{mIU} / \mathrm{L}$ ) or elevated TSH (but $<10 \mathrm{mIU} / \mathrm{L}$ ) had initial TSH $<0.6$ and $>3 \mathrm{mIU} / \mathrm{L}$, respectively. With initial TSH between 0.6 and $3 \mathrm{mIU} / \mathrm{L}, 99.5 \%$ of the subjects remained euthyroid after 5 years. Thus, repetition of TSH in this subgroup detected alterations in only one of every 200 retested subjects and even these few individuals with altered TSH did not require treatment. A known previous study demonstrated that $98 \%$ of individuals with initially normal TSH continued to present normal TSH when retested within an interval of 5 years (6). However, important limitations of that study were (i) its retrospective design, (ii) only patients with known thyroid disease were excluded but not individuals at high risk for dysfunction, and (iii) the second TSH was obtained on average 19 months after the first measurement (6). Furthermore, that study was conducted exclusively in the Israeli population (6).

We highlight some characteristics of our study. This was a prospective study and the reassessment rate was high $(85 \%)$. The interval to reassessment was exactly that recommended by some societies (1-3), including SBEM (2). Because this is a current recommendation in Brazil (2), we believe it is important to conduct a study in our country that evaluates this interval for TSH repetition. To our knowledge, no such study exists. On the other hand, it is important to note that the results reported here apply to individuals without known thyroid disease or without the risk factors for dysfunction listed in Table 1. Although measurement of antithyroid peroxidase antibodies (TPOAb) or ultrasonography (US) is not indicated in these individuals, the results could be different if TPOAb are positive or US is altered. The great stability in thyroid function observed after 5 years was limited to subjects with initial TSH between 0.6 and $3 \mathrm{mIU} / \mathrm{L}$. Finally, the results permit us to conclude that the recommended interval of 5 years (1-3) seems to be too short to reevaluate thyroid function, but the appropriate interval cannot be defined and it cannot be stated whether repetition would only be indicated if any clinical suspicion appears.

In conclusion, in this prospective Brazilian study performed in adults without known thyroid disease or risk factors for thyroid dysfunction (Table 1) who exhibit TSH between 0.6 and $3 \mathrm{mIU} / \mathrm{L}$, TSH repetition within the recommended interval of 5 years (1-3) was not cost-effective. Two hundred reassessments were necessary to detect a single case of altered TSH, which even did not result in immediate treatment.

Disclosure: This work was supported by the Brazilian National Council for Scientific and Technological Development (CNPq) through a productivity fellowship granted to P.W.R. The initial evaluation of one of the studies (4) was partly supported by Sanofi-Aventis.

\section{REFERENCES}

1. Ladenson PW, Singer PA, Ain KB, Bagchi N, Bigos ST, Levy EG, et al. American Thyroid Association guidelines for detection of thyroid dysfunction. Arch Intern Med. 2000;160:1573-5.

2. Carvalho GA, Perez CL, Ward LS. The clinical use of thyroid function tests. Arq Bras Endocrinol Metabol. 2013;57:193-204.

3. Glenn GC, Laboratory Testing Task Force of the College of American Pathologists. Practice parameter on laboratory panel testing for screening and case finding in asymptomatic adults. Arch Pathol Lab Med. 1996;120:929-43.

4. Rosario PW, Xavier AC, Calsolari MR. TSH reference values for adult Brazilian population. Arq Bras Endocrinol Metabol. 2010;54:603-6.

5. Rosario PW, Calsolari MR. TSH reference range in older adults: a Brazilian study. Arq Bras Endocrinol Metabol. 2014;58:389-93.

6. Meyerovitch J, Rotman-Pikielny P, Sherf M, Battat E, LevyY, Surks MI. Serum thyrotropin measurements in the community: fiveyear follow-up in a large network of primary care physicians. Arch Intern Med. 2007;167:1533-8.

7. Rosario PW. Natural history of subclinical hyperthyroidism in elderly patients with TSH between 0.1 and $0.4 \mathrm{mIU} / \mathrm{l}$ : a prospective study. Clin Endocrinol (Oxf). 2010;72:685-8.

8. Huber G, Staub JJ, Meier C, Mitrache C, Guglielmetti M, Huber P, et al. Prospective study of the spontaneous course of subclinical hypothyroidism: prognostic value of thyrotropin, thyroid reserve, and thyroid antibodies. J Clin Endocrinol Metab. 2002;87:3221-6.

9. Rosario PW, Carvalho M, Calsolari MR. Natural history of subclinical hypothyroidism with $\mathrm{TSH} \leq 10 \mathrm{mIU} / \mathrm{l}$ : a prospective study. Clin Endocrinol (Oxf). 2016;84:878-81.

10. Sgarbi JA, Teixeira PF, Maciel LM, Mazeto GM, Vaisman M, Montenegro Junior RM, et al.; Brazilian Society of Endocrinology and Metabolism. The Brazilian consensus for the clinical approach and treatment of subclinical hypothyroidism in adults: recom- 
mendations of the thyroid Department of the Brazilian Society of Endocrinology and Metabolism. Arq Bras Endocrinol Metabol. 2013;57:166-83.

11. Brenta G, Vaisman M, Sgarbi JA, Bergoglio LM, Andrada NC, Bravo PP, et al.; Task Force on Hypothyroidism of the Latin American Thyroid Society (LATS). Clinical practice guidelines for the management of hypothyroidism. Arq Bras Endocrinol Metabol. 2013;57:265-91.

12. Ross DS, Burch HB, Cooper DS, Greenlee MC, Laurberg P, Maia AL, et al. 2016 American Thyroid Association Guidelines for Diagnosis and Management of Hyperthyroidism and Other Causes of Thyrotoxicosis. Thyroid 2016;26:1343-421. 